\title{
A produção de serviços de saúde mental: a concepção de trabalhadores
}

\author{
The production of mental health services: \\ the conception of the workers
}

Célia M aria Sivalli Campos 1

Cássia Baldini Soares 1

\footnotetext{
1 Departamento de Enfermagem em Saúde Coletiva da Escola de Enfermagem, USP. Av. Dr. Enéas de Carvalho Aguiar 419, 05403-000, São Paulo SP. celiasiv@usp.br
}

Abstract The object of this study is the production of mental health service. It is composed by working processes organized to improve the object of the health care, through institutions and knowledge, technology and health practices. The aim of this study was to describe the conceptions of the workers of different mental health services on the production of these services. The workers took a specialization course in mental health technologies, financed by the Brazilian M inistry of $\mathrm{H}$ ealth. Data were collected during a class period, with previous participant's authorization. Among the workers of the Psychiatry $\mathrm{H}$ ospitals, $\mathrm{M}$ ental $\mathrm{H}$ ealth $\mathrm{Am}$ bulatories and $\mathrm{H}$ ealth $\mathrm{C}$ are $\mathrm{U}$ nits, the conception of the health illness-process was multifactorial and individual centred. At the Psychosocial Attention Center (PAC) the conception appeared to be similar to the theory of the social determination. The object of the assistance was the sick person or even the illness symptom, but PAC workers linked the sick person to his "social net". The challenge is to understand the social determination of the mental health-illness process and to redefine working process, in order to act not only on curing but also on preventing mental health problems.

Key words $\mathrm{H}$ ealth services, Public health, $M$ ental health, D elivery of health care
Resumo Este artigo trata da produção de serviços de saúde mental. 0 objetivo foi descrever as concepções de serviços de saúde mental de trabalhadores de diferentes serviços de saúde mental do município de São Paulo, que fizeram o curso de especialização em tecnologias em saúde mental. No âmbito hospitalar, ambulatorial e da unidade básica de saúde, a concepção de saúde-doença é multifatorial e centrada no indivíduo. Já no centro de atenção em saúde mental (CAPS), a concepção aproximou-se da teoria da determinação social. Q uanto ao processo de trabalho, o objeto recortado foi predominantemente 0 indi víduo doente e até mesmo o sintoma da doença, distinguindose no CAPS uma concepção que rel aci ona 0 usuário à sua "rede social". 0 desafio éavançar o enten dimento da concepção do processo saúde-doença e redefinir processos de trabalho, pautados no âmbito dos determinantes e não somente no dos resultados do processo saúde-doença.

Palavras-chave Produção de serviços de saúde, M odelo de aten ção, Saúde mental, Saúde col etiva 


\section{Introdução}

O objeto deste estudo é a produção de serviços em saúde mental, entendida como um conjunto de práticas assistenciais norteadas pelas diretrizes da política social pública e que se concretiza num determinado "espaço geossocial".

Tradicionalmente a organização do trabaIho em saúde mental se baseia num modelo de atenção que toma como matriz teórica uma compreensão orgânica de saúde-doença, que se concretiza em práticas assistenciais de inter ven ção focalizadas na sintomatologia e tendo como meio, quase que exclusivamente, os hospitais psiquiátricos (Pitta-H oisel, 1984; Amarante, 1995; Campos, 1978).

As transformações do modelo de assistência em saúde que vêm se consolidando desde a Constituição de 1988 e da lei 8.080/90 - que estipulou os princípios do Sistema Ú nico de Saúde brasileiro, invocando a universalidade, a integral idade e a igualdade da assistência imprimiram ao campo da saúde mental o entendimento da saúde-doença como processo social e, coerentemente, a conseqüente proposição de um modelo de atenção em saúde concretizado em práticas assistenciais de desinstitucional ização.

Partindo do pressuposto de que existe uma fragilidade na articulação entre as proposições advindas do SUS - e particularmente, da Reforma Psiquiátrica - e a consecução na saúde mental na forma de model os assistenciais coerentes, este estudo objetiva descrever as concepções sobre produção de serviços de saúde mental de trabalhadores de diferentes serviços de saúde mental do município de São Paulo, que freqüentaram o curso de especial ização em tecnologias em saúde mental, da Escola de Enfermagem da U niversidade de São Paulo/M inistério da Saúde.

\section{Referencial teórico}

0 estudo parte da compreensão dequeo processo de produção de serviços de saúde insere-se no setor terceiro da economia, val endo-se de diversos processos de trabal ho organizados com a finalidade de aperfeiçoar o objeto, utilizando meios (instituições do território) e instrumentos (saberes, tecnologias, práticas, força de trabalho); e o trabalho em si (dinâmica, organização e divisão do trabalho)
(Queiroz e Salum, 1996).

Entende-se trabal ho como uma transformação intencional de um dado objeto, respondendo a necessidades (M endes Gonçalves, 1992), que não são individuais, são coletivas. Dessa forma, o trabalho tem como finalidade responder às necessidades de um determinado grupo, o que lhe confere uma dimensão social, e se transforma nos diferentes momentos do desenvolvimento do conhecimento e da vida em sociedade.

No modo de produção capitalista a finalidade do trabal ho é produzir o lucro, transformando o trabal ho não mais em uma relação de intercâmbio com a natureza para satisfazer as necessidades vitais, mas em um trabaIho al ienado que responde às necessidades do capital (Antunes, 2000).

No trabalho em saúde, as necessidades podem ser traduzidas nas demandas de saúde, que vão além das carências dos sujeitos que procuram os serviços... no caso da saúde, o usuário de um serviço vai atrás de um consumo de al go (as ações de saúde) que tem um valor de uso fundamental, caracterizado como sendo o de permitir que a sua saúde seja ou mantida ou restabelecida e, assim, a troca lhe permite 0 acesso a algo com um valor de uso inestimável -, cuja finalidade é mantê-lo vivo e com autonomia para exercer seu modo de caminhar na vida (M erhy, 1997).

Para produzir serviços de saúde que respondam às necessidades em saúde de um determinado grupo exige-se um modelo de atenção, operacionalizando assim a política social pública que estabelece saúde como um direito e determinando que a produção de serviços de saúde não tome como finalidade 0 lucro.

A construção de um modelo de aten ção, voltado à satisfação das necessi dades de saúde, requer uma articulação entre uma dada concepção do processo saúde-doença e um conjunto de práticas, que exige uma consistência interna entre os el ementos constitutivos do processo de trabal ho - objeto, finalidade, instrumentos e a ação dos trabal hadores- para "efetivamente objetivar-se em um produto" (M endes Gonçalves, 1992).

U ma vez que a concepção do processo saúde-doença que vem norteando a política pública a partir da constituição do SU S no país foi ampliada ao considerar os determinantese condicionantes do processo, as práticas em saúde mental devem então responder às ne- 
cessidades ou demandas por saúde mais ampliadas e menos distorcidas do que as necessidades restritas ao âmbito dos resultados do processo saúde-doença (doença propriamente dita) - traduzidas em demandas por serviços de saúde -, procurando englobar aquelas dimensões que se situam no âmbito dos determinantes, das raízes dos problemas de saúde (formas de inserção no trabal ho e na vida dos diferentes grupos sociais, na reprodução da sociedade) - melhor respondidas por políticas públicas intersetoriais (Breilh, 1991).

Para a saúde coletiva, essa ampliação significa tomar o conceito da determinação social para explicar o processo saúde-doença, buscan do operacionalizá-lo em práticas assistenciais que respondam aos problemas e necessidades de saúde, tanto no âmbito dos determinantes quanto dos resultados.

Essas tentativas de operacionalização do SU S em modelos de atenção, ou tecnoassistenciais (Silva J r., 1998) subordinam-se aos encaminhamentos do Estado, que por sua vez adere a um projeto econômico social, na atualidade o projeto neoliberal.

Há uma disputa na sociedade civil, tentando-se implementar model os que vão desde o hegemônico, passando pelo que se considera como o politicamente possível, até propostas alternativas que radicalizam o conceito de reprodução social na constituição dos perfis epidemiológicos. 0 conceito de perfis epidemiológicos vem sendo desenvolvido pela epidemiologia crítica, sustentando que são compostos pelos perfis de reprodução social (formas de trabalhar e de viver) e os perfis saúdedoença (resultado do embate entre os potenciais de fortalecimento e desgaste, oriundos das formas de trabalhar e de viver dos diferentes grupos sociais) (Breilh e Granda, 1986; Laurell e N oriega, 1989; Facchini, 1995; Queiroz e Salum, 1997).

O u seja, significa sair do circuito fechado de modalidades de atenção institucionais tradicional mente instauradas para responder às necessidades do sujeito acometido por um transtorno mental, como se este fosse inerente e produzido unicamente pelas dinâmicas psíquicas dos sujeitos inscritos no seu grupo social, para inventar um modelo de atenção alicerçado no entendimento de que os problemas e as necessidades de saúde são decorrentes das formas como os grupos se inserem na reprodução social.

\section{Procedimentos metodológicos}

\section{Fontes de informação}

Tomou-se como referência o exercício realizado durante o desenvolvimento do módulo IV - modelos tecno-assistenciais em saúde mental, no curso de especialização em tecnologias em saúde mental, da Escola de Enfermagem da U niversidade de São Paulo/M inistério da Saúde, em agosto de 2001.

Participaram 18 trabal hadores que se dividiram em 5 grupos, de acordo com o tipo de serviço no qual desenvolviam suas atividades (unidade básica de saúde, hospital psiquiátrico, enfermaria de psiquiatria em um hospital geral, ambulatório de saúde mental, centro de atenção psicossocial).

Foi-Ihes solicitado que preenchessem um roteiro, cujo tema era o processo de produção do serviço de saúde no qual desenvolviam suas atividades. Constavam do rotei ro os seguintes subtemas: objeto de trabalho; finalidade do trabalho; meios e instrumentos do trabalho; organização e divisão do trabal ho; concepção do processo saúde-doença (Salum et al., 1996).

Todos os participantes assinaram o termo de consentimento livre e esclarecido, concordando que o material do exercício pudesse ser utilizado para pesquisa, atendendo à Resolução 196/96 (Brasil, 1996).

A sistematização do material coletado foi realizada de acordo com os subtemas propostos no exercício, analisando-os conforme mantivessem correspondência ou não com as seguintes concepções teóricas: determinação social do processo saúde-doença (Laurell, 1983) e processo de produção de serviços de saúde (Queiroz \& Salum, 1996).

\section{Resultados}

No que diz respeito ao processo de produção de serviços de saúde, no subtema objeto de trabal ho, os diferentes serviços de saúde propuseram diferentes recortes.

A unidade básica de saúde recortou como objeto de trabalho a queixa, o pedido e a pessoa que os traz. 0 hospital psiquiátrico tomou como objeto de trabalho os sintomas apresentados pelos usuários deste serviço. Já na enfermaria de psiquiatria de um hospital 
geral os trabal hadores apontaram para o paciente e sua família como o objeto. Os trabaIhadores do ambulatório de saúde mental referiram ser o sujeito em adoecimento psíquico o objeto de trabalho. Quanto ao centro de atenção psicossocial, o objeto de trabal ho proposto foi o usuário, quetraz sua doença etambém sua rede social (moradia, família, trabaIho, relacionamentos, lazer, cultura, etc.).

Da mesma forma, os trabalhadores dos diferentes serviços de saúde apontaram, no que diz respeito ao processo de produção de serviços de saúde, diferentes recortes no subtema finalidade do trabal ho.

A unidade básica de saúde recortou como finalidade do trabal ho a melhora da qualidade de vida e a cura, entendida como sinônimo de remissão da queixa, a integração psicossocial, a reinserção social e familiar ea organização psíquica da pessoa que procura a unidade. 0 hospital psiquiátrico tomou como finalidade do trabalho a diminuição e/ ou eliminação dos sintomas apresentados pel os usuários desse serviço. Já na enfermaria de psiquiatria de um hospital geral, os trabalhadores apontaram para a reabilitação e a reinserção social como sendo a finalidade do trabaIho. Os trabal hadores do ambulatório de saúde mental referiram ser a promoção da saúde mental do sujeito em adoecimento psíquico a finalidade do trabalho. Quanto ao centro de atenção psicossocial, a finalidade do trabal ho apareceu identificada com um projeto que aponte para uma melhor qualidade de vida.

No que diz respeito ao processo de produção de serviços de saúde, no subtema meios e instrumentos do trabalho, os trabalhadores dos diferentes serviços de saúde também propuseram diferentes alternativas.

Os trabalhadores da unidade básica de saúde apontaram o tratamento, pautado no saber clínico e psicossocial, a estrutura física da unidade, a pré-consulta (verificação dos sinais vitais), os encaminhamentos para as diferentes especialidades, a anamnese, o exame clínico, os exames laboratoriais e radiológicos como instrumentos do trabal ho desenvolvidos naquela unidade. 0 hospital psiquiátrico destacou como instrumentos: a estrutura física, os medicamentos, as internações, as visitas dos familiares, a contenção física, se necessária, os materiais e o saber clínico. Já na enfermaria de psiquiatria de um hospital geral foram el eitos como instrumentos: a medicação, à qual foi atribuído um papel funda- mental, mas também o espaço físico, a equipe multiprofissional, o saber profissional traduzido num projeto terapêutico, os equipamentos hospitalares e os materiais de consumo. Os trabalhadores do ambulatório de saú de mental apontaram a utilização de saberes técnicos (valises dura, leve dura e leve) (M erhy, 1998), referindo-se à terminologia utilizada para descrever a tecnologia que viabiliza os procedimentos, como as máquinas, os saberes e as relações), como instrumentos de trabal ho. No centro de atenção psicossocial foram apontadas estrutura física, os trabalhadores, e as tecnologias, focalizando a importância da tecnologia leve. Além desses, propuseram mecanismos que facilitem e modifiquem as condições de acesso ao serviço e as ações intersetoriais, como instrumentos do trabal ho.

Q uanto à organização e divisão do trabaIho, a unidade básica de saúde a descreveu através do percurso que o usuário faz na unidade, que atende a demanda espontânea da sua região de abrangência, desde a recepção desse usuário, que passa por uma triagem, é encaminhado para a equipe técnica ( $p$ sicologia, fonoaudiol ogia, terapia ocupacional, fisioterapia e enfermagem) e é encaminhado para a consulta médica e tratamento, ou é encaminhado para outro serviço.

Da mesma forma, os trabal hadores do hospital psiquiátrico identificaram a organização e divisão do trabal ho segundo o fluxo do usuário na instituição, apontando que o início do percurso é na admi ssão médica e do enfermeiro, passando por um atendimento multidisciplinar. A pós a internação há avaliação contínua pela equipe técnica, até a alta (médica ou com participação da equipe). Descreveram a organização do trabal ho pelos diferentes setores: serviço de nutrição, serviço de limpeza, serviço de segurança, equipe técnica, enfermagem eadministração.

$\mathrm{N}$ a enfermaria de psiquiatria de um hospital geral, a descrição da organização do trabaIho foi feita segundo os processos de gerenciamento: "administrador, diretor clínico, coordenação técnica e gerência de enfermagem".

No ambulatório de saúde mental os profissionais apontaram que o trabalho é dividido entre o "saber técnico" e a realização do trabal ho ("recepção, administração, direção, fluxograma, programas") e o trabalho é "organizado por uma hierarquia taylorista".

No CAPS o trabal ho é dividido de acordo com a as funções ("corpo administrativo - 
chefe e auxiliares; corpo técnico - equipe multidisciplinar; corpo de apoio - segurança, cozinheiras, faxineira e comunidade").

Quanto à concepção do processo saúdedoença que orienta a produção dos serviços de saúde, também os diferentes equipamentos apontaram para diferentes compreensões.

$\mathrm{Na}$ unidade básica de saúde, o entendimento do processo saúde-doença partiu do pressuposto da identificação de saúde com normalidade e dos sintomas como al go que está "fora das regras" e também apontaram a influência de fatores sociais no processo de adoecimento.

Os trabal hadores apontaram que no hospital psiquiátrico o processo saúde-doença está relacionado a fatores sociais, econômicos e culturais (abandono familiar; falta de referência familiar; desestruturação familiar; preconceito; dificuldade de adesão no tratamento extra-hospitalar; dificuldade de absorção do paciente na rede de atenção à saúde mental; referência cultural do hospital/manicômio; favorecimento da família enquanto 0 paciente está internado; falta de recursos financeiros para tratamento adequado).

Os trabal hadores da enfermaria de psiquiatria de um hospital geral referiram que 0 processo saúde-doença tem uma causa predominantemente biológica, centrada no modelo médico (organicista), baseada no diagnóstico psiquiátrico, que é construído através da observação de sintomas; embora essa seja a concepção predominante, informaram que há outras concepções em disputa, apontando para a reabilitação psicossocial, conceito pautado na teoria da determinação social do processo saúde-doença mental.

Quanto à concepção do processo saúdedoença que rege a produção de serviços de saúde do ambulatório de saúde mental, foi apontado 0 entendimento do sujeito como sen do constituído dentro de um processo bi opsicossocial, portanto um processo complexo permeado por várias áreas. Entendem que no adoecimento mental entram em questão a complexidade de fatores que constituem o sujeito.

Os trabalhadores do centro de atenção psicossocial referiram partir do pressuposto da complexidade do usuário [ deste serviço e por isso pensaram] o processo de adoecimento [ centrado] no campo das relações, entendendo-as do micro ao macro [social]. Descreveram como dimensão microssocial as relações so- ciais no âmbito da singularidade ( relação fiIho-mãe/família e a determinação biológica do acometimento); como dimensão macrossocial as relações no âmbito estrutural (de trabalho, de educação/cultura, etc.).

\section{Discussão}

A noção de saúde como normalidade e de doença como ruptura dessa normalidade, presente no discurso dos trabal hadores da unidade básica de saúde, expressa uma vez mais a forte presença do positivismo funcionalista que desde a concepção da teoria das relações entre o normal e o patológico - quando a doença passa a ser objeto de estudo da ciência - concebe a doença como desarmonia, como resultado da perturbação de um estado de regularidade e de equilíbrio. Afasta-se portanto de uma visão histórico-crítica, que concebe o homem como sendo muito mais que o seu corpo e que propõe que a nor mal idade deva ser entendida para além do funcionamento normal do organismo, incorporando as dimensões histórico-processuais de transformação das necessidades e idéias, na relação do homem com a vida social (Canguilhem, 1982).

Para os trabal hadores do hospital psiquiátrico a concepção do processo saúde-doença está relacionada a diversos fatores, que coexistem e têm igual valoração na determinação de tal processo, remetendo à teoria multicausal da doença.

A teoria da multicausalidade, que se consolidou na década de 1960 protagonizada por M ac M ahon, propôs um marco de interpretação do processo saúde-doença cujo propósito era descobrir as relações que favorecessem as possibilidades de prevenção da doença, intervindo na sua cadeia causal através da supressão ou modificação das variáveis intervenientes no surgimento do problema, através de medidas coletivas de controle (Breilh e Granda, 1986).

U ma versão mais dinâmica dessa teoria foi o model o proposto por Leavell e Clark, o da tríade ecológica. Entendia-se, nesse modelo, que os fatores condicionantes do aparecimento da doença (ambiente, hospedeiro eagente) encontravam-se na natureza interrelacionados eem equilíbrio. Assim, o comportamento anormal de um desses fatores desencadeava a doença, à medida que ocorresse a ruptura do equilíbrio de todo o sistema (Breilh e Granda, 
1986). Estabelecido o desequilíbrio, a doença era identificada como um processo biológico do indivíduo (Laurell, 1983).

Essa teoria não considera as profundas diferenças sociais entre os sujeitos, reduzindo a determinação da doença a fatores eminentemente biológicos, portanto restringindo as medidas interventivas ao âmbito das biológico-ecológicas (N unes, 1983).

$\mathrm{N}$ a enfermaria psiquiátrica $\mathrm{o}$ entendimento do processo saúde-doença é associado a uma causa predominantemente biológica. Essa visão essencialmente biológica da saúdedoença tem sua correspondência na prática assistencial, geral mente instaurada no modelo hospitalar, de cuidado especializado, individualizado e curativo e dessa forma, restringindo-se ao paciente, reduz quase que completamente a possibilidade de incorporar a dimensão do social (N unes, 1983).

No ambulatório de saúde mental a concepção do processo saúde-doença estava associada ao entendimento de que o sujeito é constituído por uma complexidade de fatores, num processo bio-psicossocial. Da mesma forma que o entendimento dos trabalhadores do hospital psiquiátrico, essa concepção se aproxima à da teoria da multicausalidade da doença, que reduz a realidade complexa a uma série de fatores, que atuam e condicionam a doença de maneira igual, não se distinguindo em peso ou qualidade. Com esse entendimento, o fator social e o biológico não se colocam como instâncias distintas, pois ambos são reduzi dos a "fatores de risco", que atuam de maneira igual (Laurell, 1983).

Os trabalhadores do centro de atenção psicossocial utilizaram, para descrever a concepção do processo saúde-doença, uma terminologia que se aproxima da concepção da determinação social, diferenciando-se dos depoimentos anteriores, na medida em que propõem uma explicação para 0 acometimento que incorpora os processos sociais. No entanto, esses processos sociais são nomeados sem hierarquização e descritos com o mesmo potencial de determinação atribuído aos fatores biológicos do âmbito da singularidade.

0 objeto foi recortado pelos trabal hadores dos diferentes serviços preponderantemente na dimensão singular - o indivíduo - e mais particularizado ainda, atendo-se ao resultado do processo saúde-doença expresso no corpo biopsíquico (Queiroz \& Salum, 1996). Esse recorte identifica-se com o objeto de trabal ho da psiquiatria, a doença manifesta (Silva et al., 2000); constatou-se semelhante apreensão no estudo real izado em uma enfermaria de psiquiatria de um hospital universitário (Kirschbaum e Paula, 2001) e em uma análise de documentos relativos à implantação de hospitais- dia no Estado de São Paulo (Campos, 1978). No centro de atenção psicossocial foi expressa uma ampliação do objeto, à medida em que foram considerados aspectos da vida e do trabal ho do indivíduo doente, embora ainda na dimensão singular, tomados como fatores isolados e desconectados de uma lógica referida ao modo de produção e atinente à dimensão estrutural.

Os trabal hadores dos diferentes serviços fizeram uma descrição da finalidade do trabalho incorporando a intenção de aprimorar a qual idade de vida dos usuários dos serviços, com vistas a possi bilitar sua convivência social. Esse resultado encontra eco em outros estudos, que apontam como finalidade do trabal ho "para além da recuperação da saúde, também [a] preservação e promoção da saúde e [a] prevenção da doença" (Campos, 1998) e a "reinserção social" (Kirschbaum e Paula, 2001).

Quanto aos instrumentos do trabalho, assim como nos documentos examinados em estudo anterior (Campos, 1998), o discurso dos trabalhadores parece ter incorporado uma terminologia que enfoca uma prática pautada em saberes multiprofissionais concretizados num projeto ter apêutico constituído de novas formas de abordagem, capazes de ampliar a intervenção, para que o sujeito se aproprie de mecanismos que favoreçam a compreensão e a administração da sua crise e do seu cotidiano.

Porém, detectou-seque ainda há uma adesão à tecnologia utilizada pela clínica, remetendo à reflexão de que embora haja uma intencionalidade de ampliar as práticas da assistência, a eleição de instrumentos mais complexos não tem necessariamente sido acompanhada de uma mudança conceitual do modelo de atenção em saúde mental.

A forma de apresentar a organização do trabalho foi bastante diversa, porém em todos os serviços é descrita de acordo com as atividades desenvolvidas pel a instituição, determinadas pelas possibilidades deatendimento oferecidas pelas diferentes categorias profissionais que compõem as equipes ou pela demanda espontânea. É possível que estas respostas estejam refletindo a pouca elaboração, no âmbito das instituições, da organização interna 
do trabalho, que deveria ser pautada em critérios estabelecidos pelos trabalhadores e pela população usuária.

É possível também que o ensino nos cursos de graduação não tenha acompanhado o processo de formulação e implementação de mudanças do modelo de atenção em saúde mental. Embora possa se verificar avanços inegáveis na direção da ampliação do objeto, tomando inclusive como referência conceitual a determinação social do processo saúdedoença mental (Guimarães e M edeiros, 2001), as aulas de campo continuam sendo desenvolvidas no âmbito interno de institui ções especializadas - hospitalares ou extra hospitalares - e focalizando a assistência ao indivíduo/família com o problema/sofrimento já instalado, não desenvolvendo ações no espaço geo-social que tomem como objeto os grupos sociais e ten ham como finalidade o aperfeiçoamento dos perfis epidemiológicos desses grupos.

\section{Considerações finais}

É possível concluir quea concepção multicausal do processo saúde-doença vem fundamentando as práticas nos diferentes serviços de saúde mental, instaurando processos de trabalho que tomam majoritariamente por objeto o sujeito em adoecimento psíquico.

Há uma ampliação do recorte do objeto, se comparado aquele da psiquiatria. Da mesma forma a finalidade do trabal ho amplia-se, porém com vistas a prevenir novas crises, recuperar a convivência social através da potencialização dos esforços individuais - indivíduo e família - para lidar com suas limitações. É inegável a apropriação de instrumentos mais complexos do que aqueles que visam à redução de sintomas, val endo-se de conhecimentos de outras áreas, instaurando práticas que embora humanizadoras não visam o enfrentamento dos determinantes estruturais do processo saúde-doença mental.

Assim, também a organização do trabalho parece estar voltada para a atenção intra-institucional aos agravosjá estabelecidos, em detrimento de ações intersetoriais no espaço geossocial.

Essa constatação parece refletir de fato os desdobramentos de operacional ização das diretrizes da Reforma Psiquiátrica.

Em um primeiro momento, a I Conferência N acional de Saúde M ental trouxe como um dos pontos de pauta a "proposta de ampliação do conceito de saúde, incluindo em seus determinantes as condições gerais de vida" (Costa-Rosa et al., 2001).

$\mathrm{Na}$ II Conferência Nacional de Saúde M ental a ênfase na crítica ao modelo econômico, que está na raiz dos problemas de saúde, foi substituída pela necessi dade de colocar em curso o processo, já iniciado, de transformação das práticas de atenção em saúde mental (Costa-Rosa et al. , 2001).

Este estudo mostra que as práticas de atenção, mesmo as pautadas nas diretrizes da Reforma Psiquiátrica, continuam atinentes ao sujeito e sua família, numa perspectiva de inclusão social do sujei to acometi do por um transtorno mental; portanto tais práticas estão ainda restritas ao âmbito dos resultados já instalados.

O desafio para a formulação de práticas que incidam no âmbito dos determinantes é compreender que a saúde mental também tem suas raízes no âmbito da reprodução social.

É preciso resgatar, tanto no plano do ensino quanto no âmbito dos serviços, os concei tos sobre saú de- doença mental que iluminaram os princípios da Reforma Psiquiátrica que parece ter se constituído como um movimento ideológico restrito - que não foram incorporados pelos sujeitos envolvidos (trabaIhadores da saúd de e usuários dos serviços de saúde), ficando comprometida dessa forma a superação das próprias práticas. 


\section{Referências bibliográficas}

Amarante P (org.) 1995. Loucos pela vida: a trajetória da reforma psiquiátrica no Brasil. Ed. Panorama, Rio de Janeiro.

Antunes R 2000. Os sentidos do trabalho: ensaio sobre a formação e a negação do trabalho. Ed. Boitempo, São Paulo.

Brasil 1996. M inistério da Saúde. Consel ho N acional de Saúde. Comissão N acional de Ética em Pesquisa CONEP. Resolução n. 196/96. Dispõe sobre pesquisa envolvendo seres humanos. M inistério da Saúde, Brasília.

Breilh J 1991. Epidemiologia: economia, política e saúde. Hucitec, São Paulo.

Breilh J \& Granda E 1986. Saúde na sociedade. Instituto de Saúde/SP-Abrasco, São Paulo.

Campos CM S 1978. Consolidando a reforma psiquiátrica no Brasil através dos hospitais-dia: a emergência das contradições entre a intencionalidade e a operacionalidade. Dissertação de mestrado. Escola de Enfermagem, Universidade de São Paulo, São Paulo.

Canguilhem G 1982. 0 normal e o patológico. (2a ed.). Ed. Forense U niversitária, Rio de Janeiro.

Costa-Rosa A, Luzio CA \& Yasui S 2001. As conferências nacionais de saúde mental e as premissas do modo psicossocial. Saúde em D ebate 25(58):18-21.

Facchini LA 1995. Trabalho materno e ganho de peso infantil. Ed. U niversitária, Pelotas.

Guimarães J \& M edeiros SM 2001. Contribuição ao ensino de saúde mental sob 0 signo da desinstitucionalização. Ciência e Saúde Coletiva 6(1):97-104.

Kirschbaum DIR \& Paula FKC 2001. 0 trabalho do enfermeiro nos equipamentos de saúde mental da rede pública de Campinas. Revista Latino-A mericana de Enfermagem 9(5):77-82.

Laurell AC 1983. A saúde-doença como processo social. In ED Nunes (org.). Medicina social: aspectos históricos e teóricos. Ed. Global, São Paulo.

Laurell AC \& N oriega M 1989. Processo de produção e saúde: trabalho e desgaste operário. Hucitec, São Paulo.

M endes Gonçalves RB 1992. Práticas de saúde: processo de trabal ho e necessidades. (Cadernos CEFOR, 1 Série textos) Centro de Formação dos Trabalhadores em Saúde da Secretaria Municipal da Saúde, São Paulo.

Merhy EE 1997. Em busca do tempo perdido: a micropolítica do trabalho vivo em saúde. In EE M erhy \& R O nocko (org.). A gir em saúde: um desafio para o público. Hucitec, São Paulo.

M erhy EE 1998. A perda da dimensão cuidadora na produção da saúde: uma discussão do modelo assistencial e da intervenção no seu modo de trabalhar a assistência. In EE M erhy. $O$ SU S em Belo H orizonte. Ed. Xamã, São Paulo.

Nunes ED 1983. Introdução. In ED Nunes (org.). M edicina social: aspectos históricos e teóricos. Ed. Global, São Paulo.

Pitta-Hoisel AM 1984. Sobre uma política de saúde mental. Dissertação de mestrado. Faculdade de M edicina, Universidade de São Paulo, São Paulo.

Queiroz VM \& Salum M JL 1996. Reconstruindo a intervenção de enfermagem em saúde coletiva face à vigilância à saúde. 48o Congresso Brasileiro de Enfermagem, São Paulo.

Queiroz VM \& Salum M JL 1997. O peracionalizando o conceito de coletivo na releitura da categoria da reprodução social. V Congresso Brasileiro de Saúde Coletiva, Lindóia.

Salum MJL et al. 1996. N ecessidades de aperfeiçoamento dos enfermeiros da Secretaria do Estado da Saúde do Estado de São Paulo diante do Sistema Ú nico de Saúde. Saúde em D ebate 51:50-8.

Silva ALA, Guilherme M, Rocha SSL \& Silva M JP 2000. Comunicação e enfermagem em saúde mental - reflexões teóricas. Revista Latino-Americana de Enfermagem 9(5):65-70.

Silva J r AG 1998. M odel os tecnoassistenciais em saúde: 0 debate no campo da saúde coletiva. Hucitec, São Paulo.

Artigo apresentado em 19/9/2002

Aprovado em 3/10/2002

Versão final apresentada em 21/10/2002 